\title{
Research note: Infant mortality in Denmark from 1835 to 1854 using the Human Mortality Database
}

\author{
Catalina Torres ${ }^{1}$ \\ ${ }^{1}$ Interdisciplinary Centre on Population Dynamics, CPop, University of \\ Southern Denmark
}

\section{Introduction}

The Human Mortality Database (HMD, 2019) is widely used for the study of mortality, as it provides high quality, comparable demographic data for more than forty national populations. For some of the countries included in that source, the time coverage exceeds 150 years, which (among other things) makes the HMD an excellent, easy-to-use tool for an initial assessment of the mortality levels in historical populations.

Mortality data from the HMD have been used in numerous studies, as researchers trust its excellent quality. While the database has certainly a high degree of reliability, it is improved continuously, as updates are made from time to time in order to correct past estimates and to add data for the most recent years. In this short research note, I explain one of those inconsistencies, concerning specifically data for Denmark from 1835 to 1854: for that period, Danish infant mortality is significantly over-estimated in the HMD, as the stillbirths are mistakenly included among the deaths at age $0^{1}$. This issue is explained below and the impact on other mortality measures is demonstrated. A partial solution to the problem is proposed at the end ('partial' because it is conceived as a possible temporary solution, until corrections are implemented in the HMD).

The aim of this short note is just to point to a specific data issue, which historical researchers using the data concerned should be aware of. Despite the particularity of the case in question, the results presented here are relevant for any study of infant mortality in the past, as the treatment of stillbirths in historical statistics is not always clear or appropriate in the light of demographic practise. This brief paper is intended as a positive note, not negative criticism: as a frequent user of the HMD, I believe the continuous improvement of this data source is of interest to the research community.

\section{Data}

For the brief descriptive analyses presented here, I use period mortality data for Denmark from the HMD, namely the annual death counts and population exposures at age $0{ }_{1} D_{0}$ and ${ }_{1} N_{0}$ respectively), estimates of the probability of dying at age $0\left({ }_{1} q_{0}\right)$ and life expectancy at birth $\left(e_{0}\right)$. The data are by sex and cover the period 1835-1950. Additionally, I use the annual number of stillbirths (males and females combined) from 1835 to 1854, as reported in Danmarks Statistik (1905).

\footnotetext{
${ }^{1}$ Last checked in Nov. 202019
} 


\section{Methods}

The annual death counts at age 0 for Denmark from 1835 to 1854 from the HMD were corrected by subtracting the number of stillbirths. While Danish data on the total number of stillbirths (males and females combined) are available on a yearly basis for the period 1835-1854, counts by sex are, to my knowledge, only for 10-year periods in Danmarks Statistik (1905). The latter volume, prepared by the national statistical office, is a summary of key developments in the Danish population during the entire $19^{\text {th }}$ century. However, as the organization of the statistical offices and the complexity of the information collected evolved rapidly during that century in most European countries, there are some aspects for which detailed information is not available, especially for the earlier decades.

The decadal distributions by sex mentioned above indicate that the proportion of female and male stillbirths remained approximately constant during the entire $19^{\text {th }}$ century in Denmark (about $43 \%$ and $57 \%$ on average, respectively for females and males). Using this information, annual estimates on the number of stillbirths by sex were obtained by applying the latter weights to the yearly data for males and females combined. The total annual number of stillbirths as well as the resulting estimates by sex are reproduced in the Appendix at the end of this document.

After subtracting the annual number of stillbirths of each sex from the death counts at age 0 from the HMD, annual life tables for 1835-1854 were computed. From the latter, two measures were selected in order to assess the impact of the corrections on infant mortality, namely the probability of dying at age $0,{ }_{1} q_{0}$ (eq.1), and life expectancy at birth, $e_{0}$ (eq. 2):

$$
{ }_{1} q_{0}=\frac{{ }_{1} m_{0}}{1+\left(1-{ }_{1} a_{0}\right){ }_{1} m_{0}},
$$

and

$$
e_{0}=T_{0} / l_{0}
$$

In the above equations, ${ }_{1} m_{0}$ is the central death rate at age $0,{ }_{1} a_{0}$ is the average personyears lived by the infants who died before age $1, T_{0}$ is the person-years lived above age 0 and $l_{0}$ is the radix of the life table (see Preston et al. 2001).

\section{Results}

During the period 1835-1854, the total number of stillbirths in Denmark increased from about 1730 to 2300. By including these cases in the numerator of the corresponding death rates, infant mortality is significantly over-estimated: instead of 15 per 1000 (as indicated in other studies, such as Johansen 2002 and Løkke 2002), the infant mortality rate based on HMD data is about 20 per 1000. This substantial difference is represented in terms of proportion of deaths at age 0 in Figure 1 (solid line), where the sharp, sudden decrease in 1855 is too pronounced to indicate a real trend. Correcting the death counts at age 0 as indicated above results in a more reasonable scenario, as indicated by the dashed line in the Figure.

Given the heavy weight of young-age mortality on life expectancy in the past, estimates of life expectancy at birth are also considerably affected: $e_{0}$ is consistently underestimated by about 2 years during the period in question (see Figure 2). This has implications for other kinds of demographic analyses. For instance, when age-contributions to changes in life expectancy are estimated using the uncorrected data, the contribution of age 0 may be over-estimated. Figure 3 shows a concrete example of this issue, where female Danish mortality was compared at two points in time (1835 and 1885), applying a simple agedecomposition method (Arriaga, 1984). Indeed, the contribution of age 0 is exaggerated when the uncorrected infant mortality rates are used, as it illustrates the large, unlikely decline from the levels in 1835-1854 to those in the 1880s (jump in 1855 indicated in Figure 


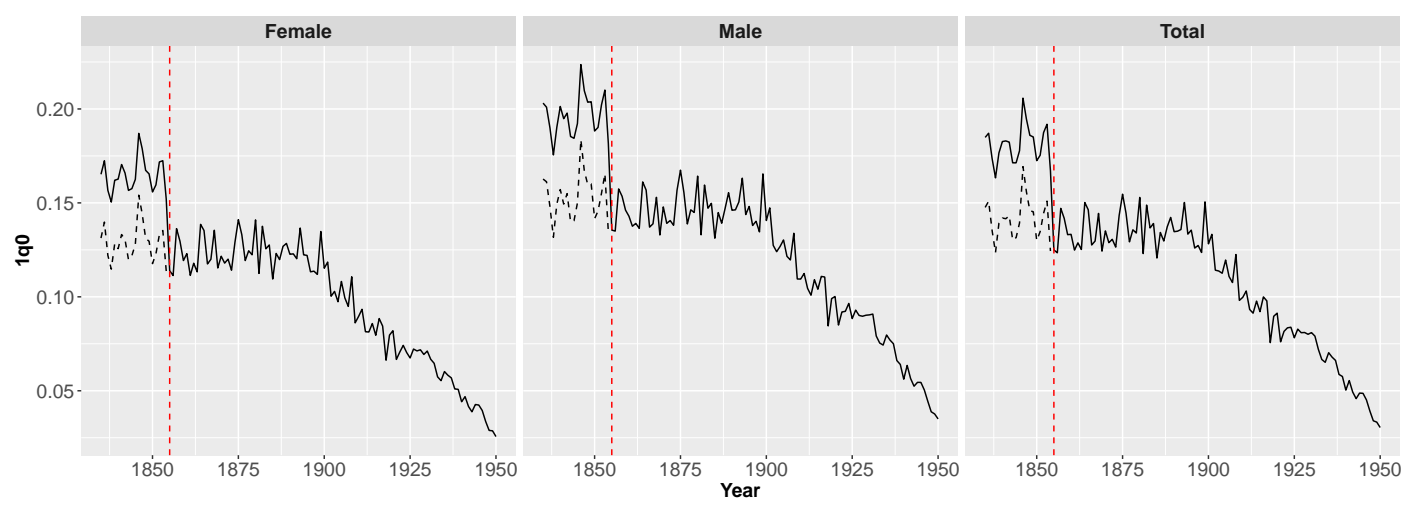

Figure 1: Probability of dying at age 0, Denmark 1835-1950, by sex

Solid black line: ${ }_{1} q_{0}$ from period life-tables in the HMD. Dashed black line: Corrected estimates for 18351854. Red dashed line in the year 1855.
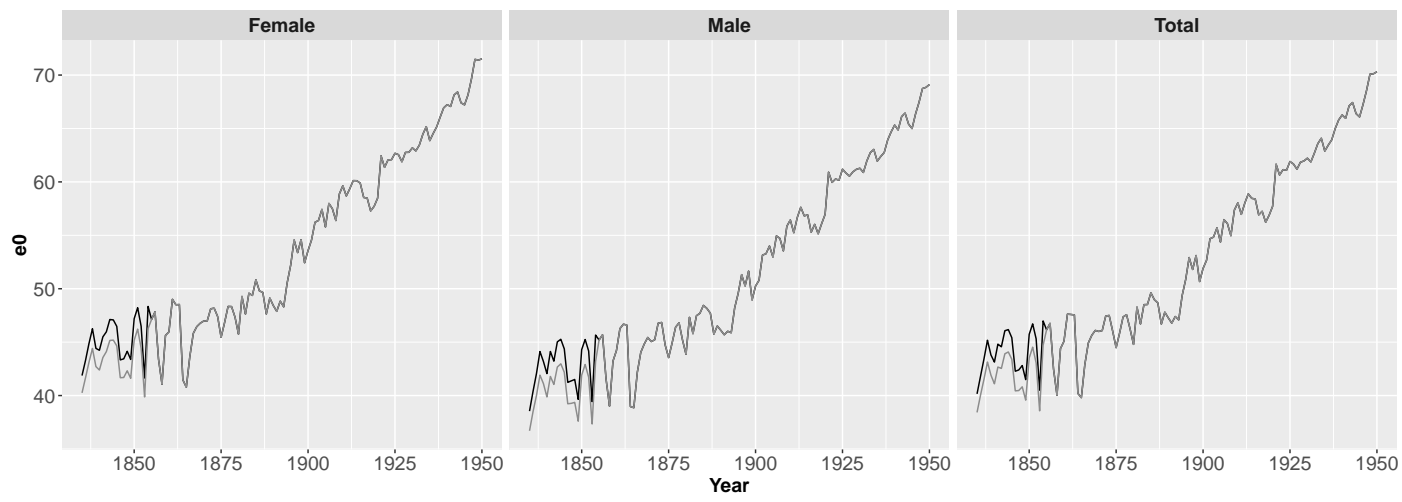

Figure 2: Life expectancy at birth, Denmark 1835-1950, males and females combined Solid grey line: Period $e_{0}$ from the HMD. Solid black line: Estimates based on the corrections at age 0 for $1835-1854$.

1). Female life expectancy at birth increased from 41.9 years in 1835 to 50.8 years in 1885 (using corrected estimates for 1835). The contribution of age 0 to that change is about 1.2 years and not 3 years, as indicated by the figure using the uncorrected data (where $e 0$ in 1835 is 40.2 ).

Finally, another example of an analysis where the use of the uncorrected data has a large impact is breakpoint analysis, where statistical methods are used in order to identify significant changes in the structure of a time-series. Torres and Oeppen (manuscript in preparation) apply a breakpoint analysis using extended series of $e_{0}$ estimates for the Nordic countries. For Denmark, the results using the uncorrected data cause an additional breakpoint to be estimated, which disappears when the corrected counts are used. A reasonable overview of the phases of the health transition in Denmark can be obtained when the breakpoint analysis is applied to the accurate time-series of $e_{0}$ estimates.

\section{Conclusion}

Including the number of stillbirths among the deaths at age 0 has a significant impact on mortality measures, especially in historical populations, where infant mortality had a heavy weight on general mortality measures such as the expectation of life at birth. An example of those issues was presented in this brief research note using data from the HMD. In that database, the stillbirths are mistakenly included with the death counts at age 0 for the years 

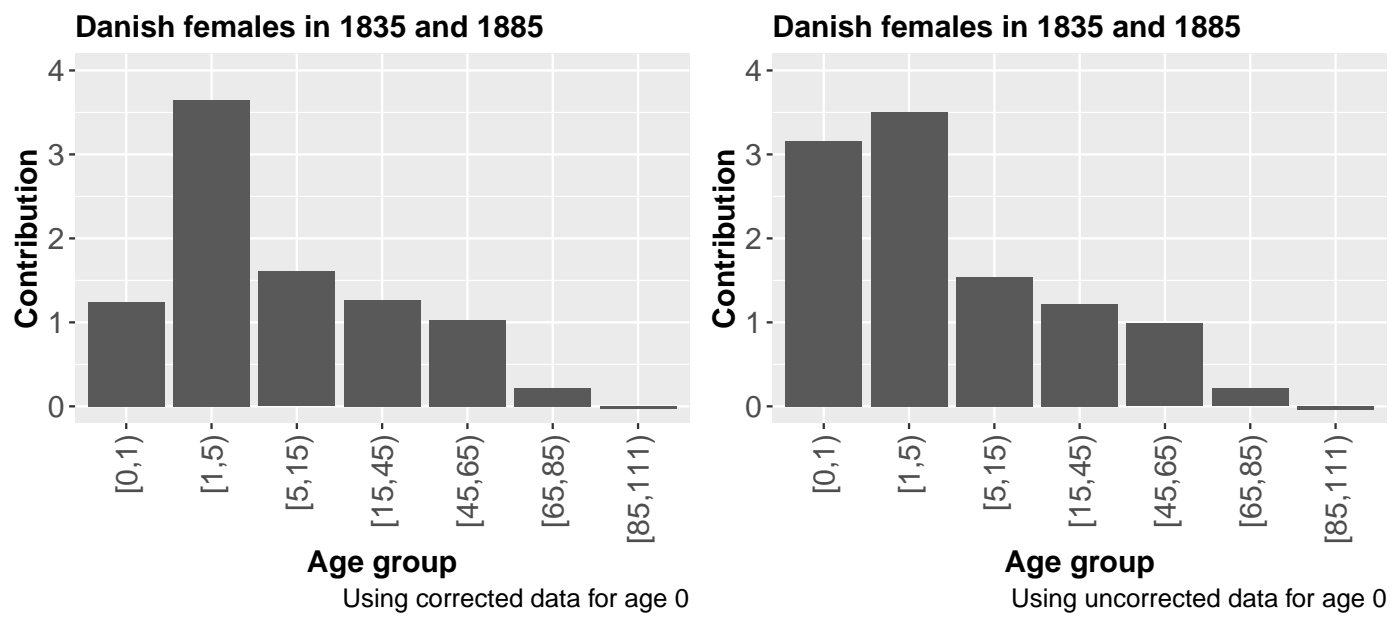

Figure 3: Age-contributions to changes in life expectancy

from 1835 to 1854 . As a result, infant mortality is overestimated and life expectancy at birth underestimated. A simple way to correct that problem was presented and the necessary data are provided in the Appendix. The latter constitute a temporary solution, until corrections are implemented in the HMD.

\section{Appendix}

Table 1: Annual number of stillbirths in Denmark, 1835-1854: total and estimates by sex

\begin{tabular}{rrrr}
\hline Year & Total $^{\mathrm{a}}$ & Females & Males \\
\hline 1835 & 1731 & 747.25 & 983.75 \\
1836 & 1701 & 734.30 & 966.70 \\
1837 & 1730 & 746.82 & 983.18 \\
1838 & 1746 & 753.73 & 992.27 \\
1839 & 1671 & 721.35 & 949.65 \\
1840 & 1823 & 786.97 & 1036.03 \\
1841 & 1844 & 796.04 & 1047.96 \\
1842 & 1761 & 760.21 & 1000.79 \\
1843 & 1835 & 792.15 & 1042.85 \\
1844 & 1840 & 794.31 & 1045.69 \\
1845 & 1824 & 787.40 & 1036.60 \\
1846 & 1775 & 766.25 & 1008.75 \\
1847 & 1862 & 803.81 & 1058.19 \\
1848 & 1956 & 844.38 & 1111.62 \\
1849 & 1992 & 859.93 & 1132.07 \\
1850 & 2113 & 912.16 & 1200.84 \\
1851 & 2020 & 872.01 & 1147.99 \\
1852 & 2268 & 979.07 & 1288.93 \\
1853 & 2243 & 968.28 & 1274.72 \\
1854 & 2291 & 989.00 & 1302.00 \\
\hline a Original data from Danmarks Statistik \\
$(1905)$
\end{tabular}




\section{References}

Arriaga, E. E. (1984). Measuring and explaining the change in life expectancies. Demography $21(1), 83-96$.

Danmarks Statistik (1905). Befolkningsforholdene $i$ Danmark $i$ det 19. aarhundrede. Statistisk Tabelværk, Femte række, Litra A. Nr. 5. Bianco lunos bogtrykkeri.

Human Mortality Database (2019). University of California, Berkeley (USA), and Max Planck Institute for Demographic Research (Germany). Data downloaded on May 10 2019.

Johansen, H. C. (2002). Danish Population History, 1600-1939. University Press of Southern Denmark.

Løkke, A. (2002). Infant mortality in nineteenth century Denmark. Regionality, feeding habits, illegitimacy and causes of death. Hygiea Internationalis 3(1), 115-149.

Preston, S., P. Heuveline, and M. Guillot (2001). Demography: Measuring and Modeling Population Processes. Wiley-Blackwell.

Torres, C. and J. Oeppen (in preparation). The health transition in the Nordic countries. 